\title{
Pharmacognostic, Phytochemical and Ethnopharmacological Potential of Cyclamen coum Mill.
}

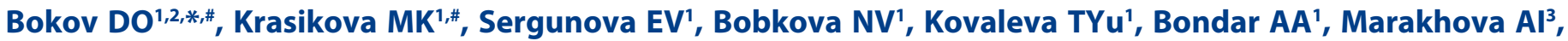 \\ Morokhina SL', Krasnyuk II', Moiseev DV ${ }^{5}$
}

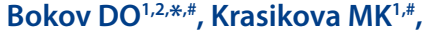 \\ Sergunova EV', Bobkova NV', \\ Kovaleva TYu', Bondar AA', \\ Marakhova $\mathrm{Al}^{3}$, Morokhina $\mathrm{SL}^{4}$, \\ Krasnyuk II', Moiseev DV ${ }^{5}$
}

'Institute of Pharmacy, Sechenov First Moscow State Medical University, 8

Trubetskaya St., bldg. 2, Moscow, 119991, RUSSIAN FEDERATION.

${ }^{2}$ Laboratory of Food Chemistry, Federal Research Center for Nutrition, Biotechnology and Food Safety, 2/14 Ustyinsky pr., Moscow, 109240, RUSSIAN FEDERATION.

3'Institute of Biochemical Technology and Nanotechnology, Peoples' Friendship University of Russia (RUDN University), 6, Miklukho-Maklaya Street, Moscow, 117198, RUSSIAN FEDERATION.

${ }^{4}$ Preparatory faculty, Financial University under the Government of the Russian Federation (Financial University), 55, Leningradsky Prospekt, Moscow, 125057, RUSSIAN FEDERATION.

${ }^{5}$ Chair of Standardization of Medicines, Vitebsk State Medical University, 27, Frunze avenue, Vitebsk, 210062, BELARUS

"Bokov DO, Krasikova MK contributed equally to this work.

\section{Correspondence}

\section{Dmitrii Bokov}

Institute of Pharmacy, Sechenov First Moscow State Medical University, 8 Trubetskaya St., bldg. 2, Moscow, 119991, RUSSIAN FEDERATION.

Laboratory of Food Chemistry,

Federal Research Center for Nutrition,

Biotechnology and Food Safety, 2/14

Ustyinsky pr., Moscow, 109240, RUSSIAN FEDERATION.

E-mail: fmmsu@mail.ru

History

- Submission Date: 16-10-2019.

- Review completed: 29-10-2019;

- Accepted Date: 26-11-2019.

DOI : 10.5530/pj.2020.12.31

Article Available online

http://www.phcogj.com/v12/i1

\section{Copyright}

(C) 2020 Phcogj.Com. This is an openaccess article distributed under the terms of the Creative Commons Attribution 4.0 International license.

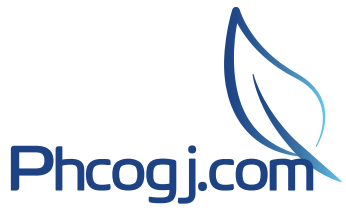

\section{ABSTRACT}

Background: This review focuses on characterization of Cyclamen coum Mill. (Myrsinaceae), composition and content of biologically active substances presented in the above-ground and underground parts, reporting use of this plant in traditional medicine, predicting possible pharmacotherapeutic effects. Materials and Methods: Various electronic search engines such as Google, Google scholar, scientific literature, electronic databases such as e-Library, Scopus, Web of Science, Pubmed had been searched and data obtained. Results: Cyclamen $\mathrm{L}$. is classified in the Myrsinaceae family now. It is a typical element of the Mediterranean flora. C. coum. is a species characteristic of the Caucasus and Crimea with rounded leaves and rounded corolla lobes, bright and pink-purple flowers. Chemical composition of biologically active substances of $C$. coum was described in sufficient detail. C. coum contains saponins (coumoside A, coumoside B, cyclaminorin, deglucocyclamin, cyclacoumin, and mirabilin lactone), sterols (stigmasterol and other related compounds), piperidine alkaloid (2- $\beta$-D-glycopyranosyl-2-undecil-3,5-dihydroxy-6-carboxypiperidine), flavonoids, phenols, tannins, cardiac glycosides. Antioxidant, antibacterial, antifungal, and antitumor activities are established for different $C$. coum extracts. Conclusion: $C$. coum can be used for the production of potential anticancer, antibacterial and antifungal drugs. It should be noted that more pharmacognostic, pharmacological studies are needed for providing further information to use this medicinal plant in the official medicine. Also, standardization procedures for a crude herbal drug should be developed.

Key words: Deglucocyclamine, Coumoside A, Coumoside B, Cyclamen coum, Cyclacumin, Cyclaminorin.

\section{INTRODUCTION}

Today over 70 thousand drugs have been registered in the Russian Federation and about $25 \%$ is produced from a crude herbal drugs. ${ }^{1}$ In the last 20 years interest in the wider use of herbal medicinal products is experiencing a revival all over the world. Herbal medicinal products (HMP) are used for treatment as well as prevention of various disease. According to World Health Organization, $60 \%$ of herbal drugs may increase in the next 15 20 years. ${ }^{2}$ In this regard, one of the actual objective of modern pharmacy, including pharmacognosy, is the research of new sources of biologically active substances. New crude herbal drugs produced from medicinal plants can serve as a source of import-substituting highly effective drugs. In this context, there are objective prerequisites for the successful implementation of the strategy for the development of the pharmaceutical industry in the Russian Federation. Over the last 15-20 years qualitative changes have occurred in terms of studying the chemical composition of medicinal plants and crude herbal drug, which is explained by the development of modern spectral and physicochemical methods of analysis. ${ }^{3-5}$

Nine different taxonomic classifications have been reported for the genus Cyclamen over the last 85 years. The genus Cyclamen is traditionally classified into the Primulaceae family. Then it was reclassified in the Myrsinaceae family, and finally, with the APG III system introduction, it was returned to the subfamily Myrsinoideae within the Primulaceae family.

The genus includes 22 species or 21 species. ${ }^{6,7} \mathrm{~A}$ high degree of polymorphism is a characteristic feature of this genus. In monograph A. Enderberg stated that many species of the genus Cyclamen demonstrate significant variability, which in combination with the popularity of these plants as ornamental plants, all the time it provoke botanists and flower growers to describe a whole army of new species". The genus Cyclamen was named because of the round shape of the rhizome (greek. kýklos "circle"). Other names: dryakva (polish dryakiew), teriak transferred to the medicinal plants of thēriacum, greek. theriacon (antidoton), "antidote, a remedy against animal poison".' Cyclamen coum (Cyclamen caucasicum, Cyclamen Kuznetsova), Cyclamen coum Mill. got its name from the island of Kos in the Aegean Sea, located next to Turkey. ${ }^{10}$

The genus Cyclamen is a typical plant for the Mediterranean flora. It is distributed in southern Europe, the Mediterranean coast, North Africa, the Crimea, the Caucasus. C. coum has an extensive areal distribution, it grows in Southern and Southeastern Europe, the Mediterranean and South-West Asia

Cite this article: Bokov DO, Krasikova MK, Sergunova EV, Bobkova NV, Kovaleva TYu, Bondar AA, et al. Pharmacognostic, Phytochemical and Ethnopharmacological Potential of Cyclamen coum Mill. Pharmacog J. 2020;12(1):204-12. 
(Turkey), in Syria and Israel. It covers Dobrudja in Romania, Strandja and the Southern Black Sea Coast in Bulgaria, Georgia. C. coum is growing in Russia: in Adygea, Krasnodar Territory and in the Crimea. It grows in the upper forest belt at an altitude of $1800 \mathrm{~m}$ (Abkhazia, Bzyb gorges). ${ }^{11-13}$ C. coum prefers shady places in coniferous, beech, mountain and deciduous forests, sometimes it grows among the roots of trees and stones. In the mountains, plant can be found at a height of $2000 \mathrm{~m}$ above sea level. ${ }^{14}$

C. coum is a non-pharmacopoeial plant, it is not used in official medicine. However, C. coum is used in traditional medicine for the treatment of hemorrhages, ecchymosis, inflammations, hemorrhoids, and cancer. ${ }^{15}$ The tubers were used in Turkish folkloric medicine for infertility treatment in women. ${ }^{16,17}$ Recent studies have shown that $C$. coum can be used as a perspective medicinal plant in clinical practice. The aim of this research is to support the theoretical substantiation of using $C$. coum in the official medicine.

\section{MATERIALS AND METHODS}

This review was carried out by a scientific search performed in August 2019, and there was no restriction in relation to the year of publication. This literature search was performed through specialized search databases (Pubmed, Scopus, Google, Google scholar, e-Library, Web of Science, scientific literature) using several combinations of the following keywords: cyclamen coum Mill., extracts, pharmacognostic characteristic, pharmacological effects, phytochemistry. The manuscript selection was based on the following inclusion criteria: articles with studies of genus Cyclamen and Cyclamen coum Mill., particularly, with keywords in the title, abstract, or full text.

In this research, about 150 articles were identified; however, 35 articles were selected as the others did not meet the inclusion criteria.

\section{RESULTS AND DISCUSSION}

\section{Botanical characteristic}

C. coum is a perennial herbaceous plant, forest ephemeroid with tuber. The height of the plants is $10 \mathrm{~cm}$ during flowering (Figure 1).

Aerial peduncles are located in the form of rosettes. Tubers are dark brown, velvety with a diameter of up to $8 \mathrm{~cm}$ (tuber of hypocotyl origin, with adventitious roots). The leaves are rounded with long petioles, there are often light spots above, the leaves are maroon-purple below. The proportion of length to width is 2.5:4. Generative peduncles are axillary, monocyclic with single flowers. The flowers are bisexual, on long pedicels. The flowers are bright, pink-purple. The perianth is double, pentamerous, symphyllous. The corolla consists of 5 petals that are up to $15 \mathrm{~mm}$ long. The corolla lobes are rounded (up to $15 \mathrm{~mm}$ long, up to $10 \mathrm{~mm}$ wide), with a small dark purple spot at the base of the petal (Figure 2, left).

Threads slightly dilated at base. Anthers are yellow, the stile is short and hides in the fauces of the corolla. The ovary is globose with reddish fuzz. There are consistent pattern in changing the color of the petals, the size of the flowers and the shape of the leaves. For example, bud-like leaves and pale pink flowers in plants from southern Turkey and Syria, bright pink flowers on the Black Sea coast of Turkey, closer to the east, the flowers are getting bigger, and the leaves are narrower. Fruit is a spherical box that opens with 5-8 serratures (Figure 2, right). ${ }^{21}$

The flowering phase begins in February-March, as soon as the snow melts. This is due to the peculiarities of the ephemeroid morphogenesis. Flowering ends in April, the plants partially or completely lose their foliage in May-June. The sprouts of vegetative and generative buds become noticeable in mid-September, the plants leave the state of rest, but they flower only in late winter - early spring. Under the conditions

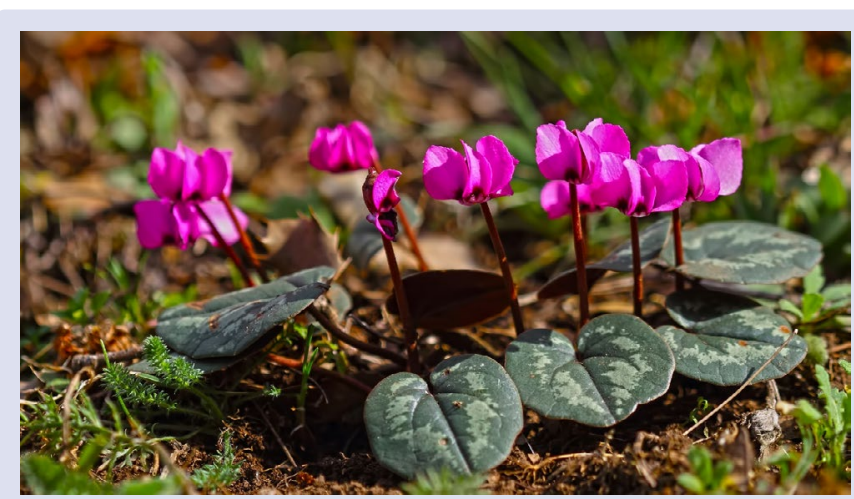

Figure 1: Cyclamen coum Mill. in flowering phase. ${ }^{18}$

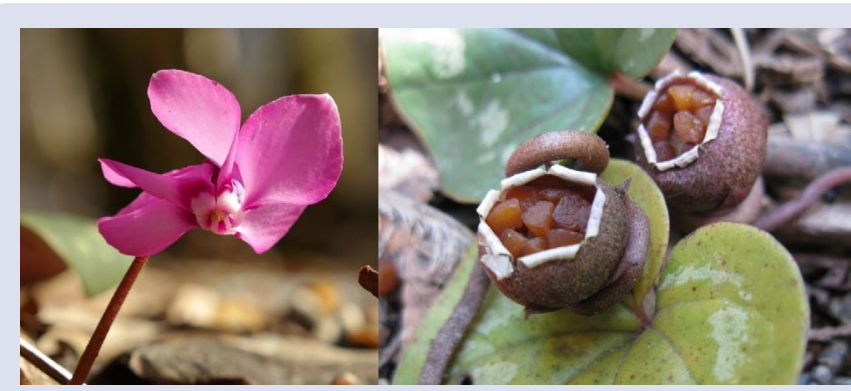

Figure 2: Flower of C. coum ${ }^{19}$ and opened fruits of C. coum with seeds..$^{20}$

of the greenhouse, C. coum awakens in mid-August, leaves and buds are formed at the beginning of autumn, flowering begins in late Novemberearly December. Similar facts are also can be observed in natural populations in years with mild winters. ${ }^{22}$

Vakhrusheva L.P. et al. described qualitative and quantitative characteristics for the different age plant groups. The number of leaves, the size of leaf blades, the length of the petiole, the number of generative peduncles, the size of the tubers were studied (Table 1). ${ }^{8}$

C. coum occupies contrasting habitats from sea level to high mountains. In this regard, the variability of the anatomical and morphological features of the C. coum depending on its distribution at different conditions (heights) was studied at the Universities of Ordu and Ondokuzmay (Ordu, Turkey). Such observations are important for understanding phenotypic rearrangement when growing plants in different environmental conditions. The authors found that the length of the petiole and the length of the internodes are significantly reduced with height increase. The length of the peduncles, the width of the bulb, the width and length of the leaves, the number of flowers also change in great value. ${ }^{23}$

\section{Harvesting, drying, storing and traditional uses of $C$. coum crude herbal drugs}

The tubers are collected from C. coum. The underground parts of the plant are harvested after the death of the aerial parts - in the middle of summer. Underground parts of plants are dug with shovels or other tools along with the ground. After harvesting, the underground organs are cleaned off the ground, by shaking off. Aerial parts and damaged areas are cut with knives. Raw materials should not be washed. After cleaning the ground, the raw material is laid out on the grass for drying. Under natural conditions, "air-shade" or solar drying can be used. Before artificial drying, raw materials are air dried for 2-3 days and accelerate the process of dehydration. Convective drying is carried out in batch or continuous dryers. Drying is considered complete when the underground organs break with a bang, rather than bend. ${ }^{24}$ 
Table 1: Characteristics of $C$. coum age groups.

\begin{tabular}{|c|c|c|c|c|}
\hline \multirow{2}{*}{ Age group } & \multicolumn{4}{|c|}{ Characteristic } \\
\hline & The length of the petiole & The form of the leaf & Length and width of the leaf & Diameter and shape of the tuber \\
\hline Germ & $1,5 \pm 0,3 \mathrm{~cm}$ & bud-like & $\begin{array}{l}1,7 \pm 0,2 \mathrm{~mm} \\
2,1 \pm 0,2 \mathrm{~mm}\end{array}$ & $\begin{array}{l}3,0 \pm 0,1 \mathrm{~mm} \\
\text { rounded }\end{array}$ \\
\hline Juvenile individuals & $3,8 \pm 0,4 \mathrm{~cm}$ & bud-like & $\begin{array}{l}0,5 \pm 0,2 \mathrm{~cm} \\
0,9 \pm 0,2 \mathrm{~cm}\end{array}$ & $\begin{array}{l}5,0 \pm 0,1 \mathrm{~mm} \\
\text { rounded with c } 2-3 \text { adventitious roots }\end{array}$ \\
\hline Immature individuals & $4,4 \pm 0,3 \mathrm{~cm}$ & bud-like & $\begin{array}{l}1,0-1,8 \mathrm{~cm} \\
1,0-2,2 \mathrm{~cm}\end{array}$ & $\begin{array}{c}9,0 \pm 0,1 \mathrm{~mm} \\
\text { Diameter : height - } 1,4: 1\end{array}$ \\
\hline Virginian individuals & $4,5-4,7 \mathrm{~cm}$ & $\begin{array}{l}\text { bud-like, } \\
2-3 \text { leaves }\end{array}$ & $\begin{array}{l}1,0-1,8 \mathrm{~cm} \\
1,0-2,2 \mathrm{~cm}\end{array}$ & $\begin{array}{l}14 \pm 0,1 \mathrm{~mm} \\
\text { flattened }\end{array}$ \\
\hline Generative individuals & $4,5-4,7 \mathrm{~cm}$ & $\begin{array}{l}\text { bud-like, } \\
\text { 3-17 leaves }\end{array}$ & $\begin{array}{l}\approx 4,4 \mathrm{~cm} \\
\approx 4,4 \mathrm{~cm}\end{array}$ & $\begin{array}{c}27-35 \mathrm{~mm} \\
\text { flattened }\end{array}$ \\
\hline
\end{tabular}

There has been insufficient research on the microscopy of cyclamen coum.

The crude herbal drugs are stored separately. All cyclamen plants are poisonous because of the cyclamin, toxic saponin contained in their fresh bulb, that is white opaque substance. This substance can absorb up to $45 \%$ water in air, swelling in water and becoming transparent, soluble in alcohol. Cyclamin is an irritant poison that causes gastroenteritis, bloody stools, dizziness, seizures, even death by asphyxiation. ${ }^{25}$

Cyclamen is especially widely known in traditional medicine as a remedy that completely and permanently cures chronic sinusitis, sinusitis, runny nose, nasal polyps and adenoids, and also treats arthritis and headaches. Alcohol tincture is prepared from tubers of cyclamen. ${ }^{26}$

\section{Impurity plants}

Other species of cyclamen may be mistakenly harvested. A group of researchers from the Chukurova University (Adana, Turkey), the Mustafa Kemal University (Hatay, Turkey), the Aegean University (Izmir, Turkey) and the Nigde University (Nowhere, Turkey) studied the morphological and anatomical features of the Cyclamen genus and the differences of some species were characterized. Significant differences are noted for the leaves characteristics (Figure 3). C. coum has roundish, bud-like leaves, the pattern is less pronounced on the upper surface of the leaf, the leaf is claret-violet from the bottom. C. persicum has a pronounced yellow-green pattern on the upper side of the leaf, the lower surface is light green. Leaves are heart-shaped. C. cilicium has matte, heart-shaped leaves with silver spots. C. pseudibericum is characterized by broad heart-shaped leaves. They are shiny, dark green with gray-green or whitish marbling; the edge is uneven.

The color of the petals is a common feature of cyclamen species. In nature, C. coum and C. pseudibericum generally have dark pink petals. C. pseudibericum is distinguished by a chocolate spot at the base of each petal (Figure 4). C. persicum has a maculation and darker margin of the petal. ${ }^{6}$

\section{Chemical composition of $C$. coum}

A group of researchers from the Karadeniz Technical University (Turkey) and the Forestry Research Institute (Trabzon, Turkey) identified triterpene saponins - coumoside A (1) and coumoside B (2) (Table 2) in the C. coum methanol extract. Crushed wet tubers of cyclamen (1500 g) were extracted by cold methanol, extract was filtered, and the filtrate was concentrated on a rotary evaporator at $30^{\circ} \mathrm{C}$. The obtained aqueous extract $(400 \mathrm{ml})$ was treated with chloroform $(150 \mathrm{ml}, 3$ times). The portion of aqueous phase $(100 \mathrm{ml})$ was evaporated in vacuum at 30 $35^{\circ} \mathrm{C}$ until dryness. The obtained crude residue $(2.5 \mathrm{~g})$ was separated using flash column chromatography and then the combined fractions were analyzed by NMR. ${ }^{27-30}$

Later, a group of researchers from Hacettepe University (Ankara, Turkey), Ankara University (Ankara, Turkey) and the Swiss Federal Institute of Technology (Zurich, Switzerland) carried out a series of phytochemical studies. In the C. coum tubers four new compounds were identified as saponins: cyclaminorin (3), deglucocyclamine (4), cyclacumin (5) and mirabilin lactone (6) (Table 2). The freeze-dried tubers $(500 \mathrm{~g})$ were chopped and extracted with methanol at reflux. The crude extract was evaporated under reduced pressure to dryness (45 g). Two methods were used for further saponins isolation. A part of the methanol extract $(15 \mathrm{~g})$ was chromatographed on silica gel, the other part $(20 \mathrm{~g})$ was fractionated by HPLC. The structure of the compounds was determined using NMR spectroscopy, mass spectrometric analysis, IR spectroscopy, and chemical methods. ${ }^{16,29}$

Researchers from the University of Vienna (Vienna, Austria) carried out acid hydrolysis of the saponin complex isolated from the tubers of $C$. coum and identified cyclamiretins A (7), C (8), D (9) and cyclamigenin A (10). They also found that, regardless of the developmental stage of the C. coum plant, deglucocyclamine content was highest in the tubers (Table 2). ${ }^{31}$ Researchers from the Karadeniz Technical University (Turkey) have isolated sterols from the whole plant - stigmasterol (11) and its related compounds. Extraction was carried out similarly as for the extraction of saponins. Extracted compounds were identified by NMR spectroscopy and GC-MS spectrometry. ${ }^{32}$

Later, the same researchers isolated glucose and piperidine alkaloid 2 - $\beta$-D-glycopyranosyl-2-undecil-3,5-dihydroxy-6-carboxypiperidine (12) (Table 2). The structure of this compound was established using NMR spectroscopy and mass-spectrometry. ${ }^{33}$

In the An-Najah National University (Nablus, Palestine) the qualitative and quantitative composition of the aerial parts of $C$. coum has been investigated. The high content of flavonoids was determined; its content was expressed in terms of quercetin and amounted $60.88 \mathrm{mg} / \mathrm{g}$ in extract. Phenols $(32.7 \mathrm{mg} / \mathrm{g}$ in terms of gallic acid) were also found in large quantities. In moderate amounts, compared with the content in other plants, tannins were investigated, its content was $11.7 \mathrm{mg} / \mathrm{g}$ in terms of catechin. Also, amino acids, steroids, reducing sugars, carbohydrates and cardiac glycosides were found in the aerial parts of the plant. ${ }^{15}$

Components of flower pigmentation (anthocyanins) have been studied in many cyclamen cultivars. ${ }^{34}$ Nevertheless, anthocyanin profile of $C$. coum remains currently uninvestigated.

\section{Pharmacological effects of $C$. coum crude herbal drugs}

In the last few years, cancer remains one of the main causes of death, and the number of victims of this disease continues to rise. Plants are a potential source of chemical compounds with antitumor and cytotoxic activity. Researchers from Turkey studied the cytotoxic effect of the extract of C. coum on cervical cancer cells and lung cancer cells. It was found that cyclamen extract has moderate cytotoxicity and causes apoptosis in both cell lines, but it acts stronger on cervical cancer cells. The authors explained this selectivity of cytotoxicity by the different 


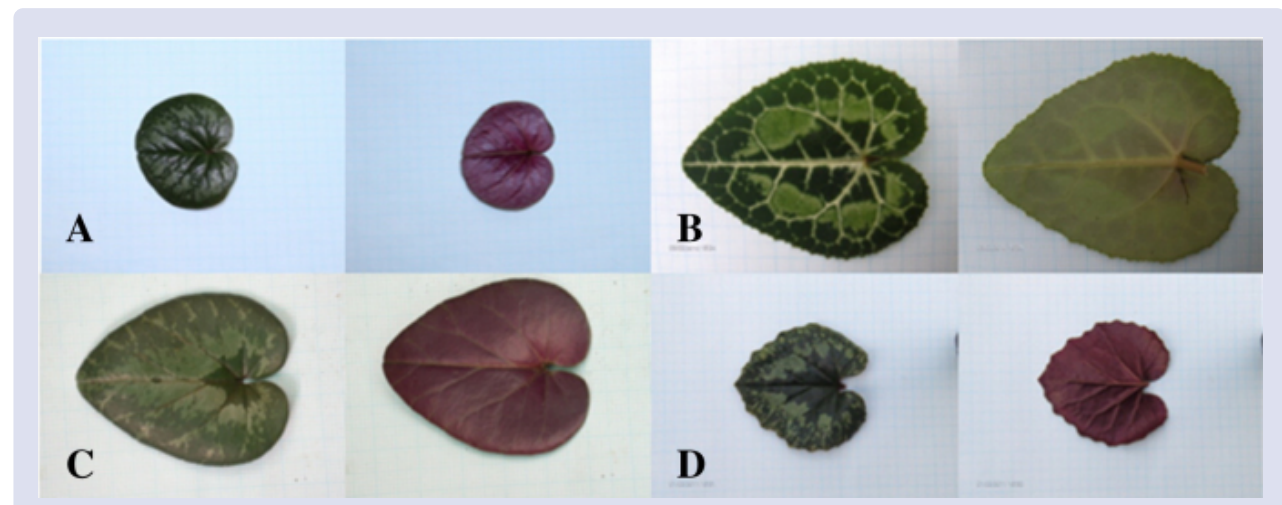

Figure 3: The upper and lower sides of cyclamen species leave. ${ }^{6}$ A - C. coum; B - C. persicum; C - C. cilicium; D-C.pseudibericum.

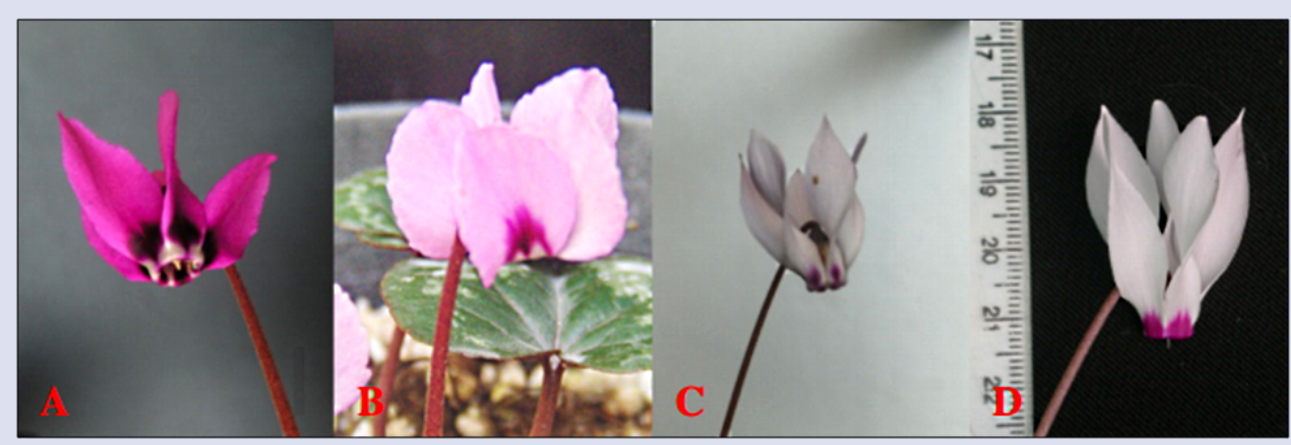

Figure 4: The colors of the petals of some cyclamen species. ${ }^{6} \mathrm{~A}-\mathrm{C}$. pseudibericum; B - C. coum; C - C. cilicium D - C. persicum.

Table 2: Chemical composition with structural formulas of C. coum.

No Compound name Part of the $\begin{gathered}\text { plant } \\ \text { Coumoside } \mathrm{A}\end{gathered}$


3

Cyclaminorin

Tubers

4

Deglucocyclamine

Tubers

Tubers

6 Mirabilin lactone

Tubers

$7 \quad$ Cyclamiretin A

Tubers

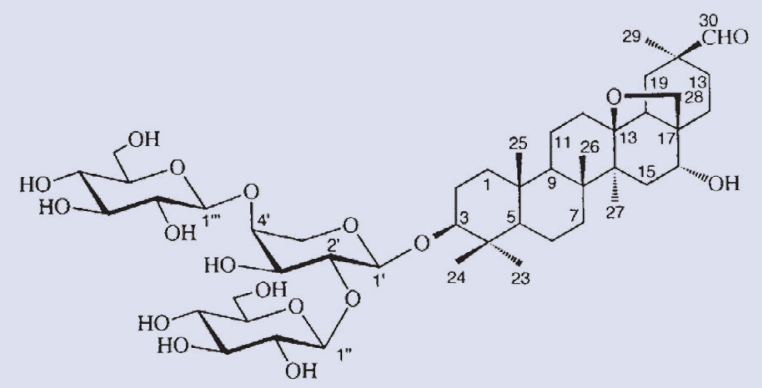


9

Cyclamiretin D Tubers

10

Cyclamigenin A

Tubers

Tubers

Tubers

2 D- glycopyranosyl-2undecil-3,5-dihydroxy-6-<smiles>CC1(C=O)CCC2(CO)C(O)CC3(C)C4=CCC5C6(C)CCC(O)C(C)(C)C6CCC5(C)C4(C)C3CC2(C)C1</smilescarboxypiperidine

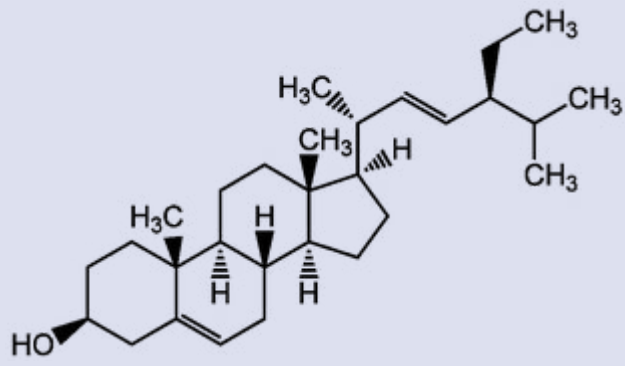

$\mathrm{OH}$

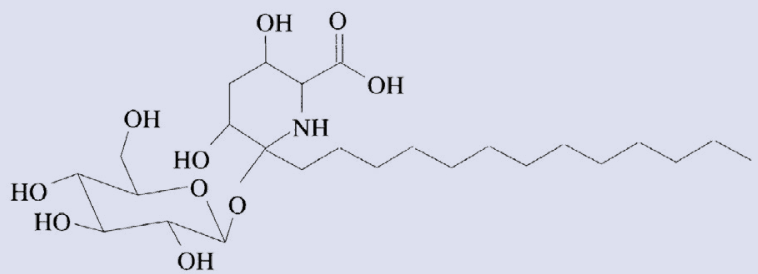

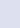

sensitivity of cells to the active substances in the extract. This study is an encouraging step in the development of a new cytotoxic drug that can be effectively used in chemotherapy. ${ }^{14}$

Saponins and phenolic compounds are the main groups responsible for the antimicrobial plants activity. The interaction of aglycone fragments of saponins and fungal membrane sterols is the main mechanism that causes the formation of transmembrane pores, it destroys the integrity and leads to membrane lysis. In the Alzahra University (Tehran, Iran) the susceptibility of three Candida strains to the C. coum tuber extract has been studied. It was found that the ethyl acetate extract did not inhibit Candida strains due to the low content of saponins, while the aqueous and $n$-butanol extracts showed significant activity. It has been shown that extracts have a significant antifungal effect in comparison with ketoconazole. Susceptibility of Candida to C. coum tuber extracts was evaluated via minimum inhibitory concentration (MIC) and minimum fungicidal concentration (MFC).

Glycosidic aqueous and $n$-butanolic phases showed antifungal activity against all the studied fungal strains, indicating the important role of sugar chains in stimulating the activity of saponin. The aqueous phase of the aglycone extract with low content of saponin and high content of phenol was the most active. The MIC and MFC of the aqueous and $n$-butanolic extracts varied from $2-32 \mu \mathrm{g} / \mathrm{ml}$ for different Candida strains. $^{35}$
A group of researchers from the Pasteur Institute of Iran (Tehran, Iran), the Alzahra University (Tehran, Iran) and the Immunoregulation Research Center (Tehran, Iran) detected the activity of the n-butanolic extract of the C. coum, it suppresses the formation of the Pseudomonas aeruginosa biofilm. This fact plays a significant role in people with cystic fibrosis since biofilm is resistant to some antibiotics due to its impermeable structure. Antibiofilm and antibacterial properties of n-butanolic extract of C. coum alone and in combination with ciprofloxacin were studied using the method of serial dilution. According to this study, an antibiotic or C. coum n-butanolic extract (at a concentration of $55 \pm 0.3 \mu \mathrm{g} / \mathrm{ml}$ ) significantly suppresses the formation of a $P$. aeruginosa biofilm, but their combination more significantly inhibits biofilm formation (concentrations of antibiotic and extract are reduced - $38 \pm 0.3 \mu \mathrm{g} / \mathrm{ml}){ }^{36}$

An-Najah National University (Nablus, Palestine) researchers evaluated the antibacterial and antioxidant activity of the methanol extract of the C. coum aerial parts due to the high content of flavonoids and phenols. ${ }^{37}$, ${ }^{38}$ Antioxidant activity (AO) was determined by spectrophotometry at a wavelength of $517 \mathrm{~nm}(\mathrm{AO}=31 \mu \mathrm{g} / \mathrm{mL})$. The MIC was determined by the method of serial dilution and its value was $6.25-12.5 \mathrm{mg} / \mathrm{ml}$ against various bacterial strains, including Staphylococcus aureus, Escherichia coli, Pseudomonas aeruginosa, and methicillin-resistant Staphylococcus aureus (MRSA). Higher activity was noted against $P$. aeruginosa (MIC 
$=6.25 \mathrm{mg} / \mathrm{ml})$, that affect the respiratory system, bones, joints, urinary tract, cause gastrointestinal infections, dermatitis, various systemic infections, especially in patients with severe burns. ${ }^{15}$

C. coum has a high level of frost hardiness and also disease resistance, thus making it a valuable source of genetic material for breeders and growers of Cyclamen species. A group of researchers from Germany has shown that somatic embryogenesis can be an effective and stable system for the regeneration and reproduction of C. coum. A protocol for isolating protoplasts from somatic embryos and suspension cultures was developed, and the culture conditions for the growth of embryogenic cultures on solid and liquid media were optimized. ${ }^{39}$

\section{CONCLUSION}

Recently, many plants have been incorporated into official medicine because of their discovered valuable properties and evidence-based medicine success. Improved methods of analysis and quality control, as well as the achievements of clinical studies show the promise of using herbal medicinal products for the prevention and treatment of various diseases. ${ }^{15}$

C. coum has an ornamental value, contains a wide range of biologically active substances: saponins, sterols, piperidine alkaloids, flavonoids, phenols, tannins, carbohydrates, and cardiac glycosides. Saponins and phenolic compounds possess antimicrobial activity, and therefore the crude herbal drug of $C$. coum can be considered as a potential antibacterial and antifungal drug. The greatest activity was found against $P$. aeruginosa, and activity in suppressing the formation of $P$. aeruginosa biofilm was also noted. Extract of $C$. coum in combination with appropriate antibiotics can serve as a promising antibiotic therapy for patients with cystic fibrosis.

C. coum extract possesses antitumor and cytotoxic effects, thus $C$. coum can be positioned as a source for the preparation of drugs for the prevention of cancer.

It should be noted that there is a need for further studies for the isolated chemical compounds to identify other pharmacological effects, as well as with the aim of possible identification of other biologically active substances. The information presented in this research work can serve as a theoretical justification for the promise of $C$. coum and the feasibility of further pharmacognostic studies of this plant, including the development of pharmacopoeial monographs and methods of quality control for crude herbal drugs to introduce drugs based on it into official medicine.

\section{ACKNOWLEDGMENT}

This paper was financially supported by "Russian Academic Excellence Project 5-100", Ministry of Education and Science of the Russian federation (the Agreement number 02.A03.21.0008).

\section{CONFLICTS OF INTEREST}

None.

\section{REFERENCES}

1. Boyko NN, Bondarev AV, Zhilyakova ET, Pisarev DI, Novikov OO. Phytopreparations, analysis of the pharmaceutical market of the Russian Federation. Research Results in Biomedicine. 2017;3(4):30-8.

2. Kurkin VA. Pharmacognosy as a methodological basis of evidence-based herbal medicine. Izvestia of Samara Scientific Center of the Russian Academy of Sciences. 2015;5(2):592-7.

3. Novikov OO, Pisarev DI, Zhilyakova ET, Malyutina AYu, Novikova MYu, Vasilyev GV. On the issue of expanding the capabilities of analytical equipment. Scientific result. Medicine and Pharmacy. 2016;2(4): 84-8.

4. Pauli, GF, Godecke T, Jaki BU, Lankin DC. Quantitative 1H NMR. Development and potential of an analytical method: an update. J Nat Prod. 2012;75(4):834-51.
5. Morozov SV, Tkacheva NI, Tkachev AV. Problems of complex chemical profiling of medicinal plants. Chemistry of Plant Raw Materials. 2018;4:5-28.

6. Curuk P, Sogut Z, Bozdogan E, Izgu I, Sevindik B, Tagipur EM, et al. Morphological characterization of Cyclamen sp. grown naturally in Turkey: Part I. S Afr J Bot. 2015; $100: 7-15$

7. Curuk P, Sogut Z, Izgu T, Sevindik B, Tagipur EM, et al. Morphological characterization of Cyclamen sp. grown naturally in Turkey: Part II. Acta Sci PolHortoru. 2016;15(5):205-24.

8. Vakhrusheva LP,Yena AV, Boldyrev EV. Cyclamen coum in the Crimea: evaluation of species morphological criteria and age stages. Optimization and Protection of Ecosystems. 2009;20:74-81.

9. Spiridonova GYa. Alphabet of flowers or German-Russian etymological dictionary of names of flowers. Izhevsk: Udmurt University; 2015.

10. Doorenbos J. Taxonomy and nomenclature of Cyclamen. Mededel Landbouwhogesch Wageningen. 1950;50(2):19-29.

11. Luchkina MA. Comparative analysis ontogenesis peculiarities Cyclamen coum Mill. And Cyclamen kuznetzovii Kotov et Czernov. Vestnik Moskovskogo universiteta. Biologiya 2010;16(2):46-51.

12. Yesson C, Culham A. A phyloclimatic study of Cyclamen. BMC Evolutionary Biology. 2006;6(1):72.

13. Debussche M, Garnier E, Thompson JD. Exploring the causes of variation in phenology and morphology in Mediterranean geophytes: a genus-wide study of Cyclamen. Bot J Linn Soc. 2004;145(4):469-84.

14. Yildiz M, Bozcuk H, Tokgun O, Karagur ER, Akyurt O, Akca H. Cyclamen exerts cytotoxicity in solid tumor cell lines: A step toward new anticancer agents? Asian Pac J Cancer Prev. 2013;14(10):5911-3.

15. Jaradat NA, Al-Masri M, Hussen F, Zaid AN, Ali I, Tammam A, et al. Preliminary phytochemical and biological screening of Cyclamen coum a member of palestinian flora. Pharmaceutical Sciences. 2017;23(3):231-7.

16. Çaliş i, Yürüker A, Tanker N, Wright AD, Sticher O. Triterpene Saponins from Cyclamen coum var. coum. Planta Med. 1997;63(2):166-70.

17. Calis T, Sticher O. Triterpene saponins from plants of the flora of Turkey. Saponins Used in Traditional and Modern Medicine. Adv Exp Med Biol. 1996;404:485500 .

18. Dogalhayat.org WordPress ile güçlendirilmiştir. Cyclamen coum Mill.

19. Available from: http://dogalhayat.org/property/cyclamen-coum/ [cited 2019 Aug 12]

20. Plantarium. The determinant of plants on-line. Open Atlas of Plants and Lichens in Russia and Adjacent Countries. Cyclamen coum Mill. Description of the taxon [cited 2019 Aug 12]. Available from: http://www.plantarium.ru/page/ image/id/605949.html

21. Plantarium. The determinant of plants on-line. Open Atlas of Plants and Lichens in Russia and Adjacent Countries. Cyclamen coum Mill. Description of the taxon [cited 2019 Aug 12]. Available from: http://www.plantarium.ru/page/ image/id/194505.html

22. Litvinskaya SA. Cyclamen coum Mill. Red Data Book of the Krasnodar Territory Plants and mushrooms. Krasnodar: Design Bureau № 1. 2007;157-8.

23. Tyuvetskaya MA. The rhythm of seasonal development (growth) of Cyclamen $L$. (Primulaceae) species in conditions of green-house culture. Bulletin of Moscow Society of Naturalists. Biological Series. 2013;118(1):61-72.

24. Ozbucak TB, Polat G, Akcın OE, Kutbay HG. The Effects of Elevation on the Morpho-Anatomical and Ecological Traits in Cyclamen coum subsp. coum Mill. Populations in the Central Black Sea Region of Turkey in Contrasting Habitats. Pol J Ecol. 2017;65(2):211-26.

25. Sorokina AA, Samylina IA. Pharmacognosy. Educational practice: Textbook Moscow: Medical Information Agency, 2011; 732.

26. Mazouz W, Djeddi S. A Biological Overview on the Genus Cyclamen. European Journal of Scientific Research. 2013;110(1):7-22.

27. Maznev N. Highly effective medicinal plants. Great Encyclopedia. - Litres, 2018.

28. Yayli N, Baltaci C, Zengin A, Küçükislamoglu M, Genç $H$. Triterpenoid saponin from Cyclamen coum. Phytochemistry. 1998;48(5):881-4.

29. Yayli N, Baltaci C, Zengin A, Küçükislamoglu M, Genç H, Küçük M. Pentacyclic Triterpenoid Saponin from Cyclamen coum. Planta Med. 1998;64(4):382-4.

30. Foubert K, Theunis M, Apers S, Vlietinck AJ, Pieters L. Chemistry, distribution and biological activities of 13,28-Epoxy-Oleanane Saponins from the Plant Families Myrsinaceae and Primulaceae. Curr Org Chem. 2008;12:629-42.

31. Connolly JD, Hill RA. Triterpenoids. Natural Product Reports. 2000;17(5):463-82.

32. Reznicek G, Jurenitsch J, RobientW, Kubelka W. Saponins in Cyclamen species: configuration of cyclamiretin $\mathrm{C}$ and structure of isocyclamin. Phytochemistry. 1989;28(3):825-8.

33. Yayli N, Baltaci C. The Sterols of Cyclamen coum. Turk J Chem. 1996;20(4):329 34. 
34. Yayli N, Baltaci C. A novel glycosidicly linked piperidine alkaloid from Cyclamen coum. Turk J Chem. 1997;21(2):139-43.

35. Akita $Y$, Kitamura $S$, Hase $Y$, Narumi I, Ishizaka $H$, Kondo $E$, et al. Isolation and characterization of the fragrant cyclamen O-methyltransferase involved in flower coloration. Planta. 2011;234(6):1127-36.

36. Sajjadi ST, Saboora A, Mohammadi P. Comparison of aglycon and glycosidic saponin extracts of Cyclamen coum tuber against Candida spp. Current Medical Mycology. 2016;2(2):40-4

37. Abdi-Ali A, Shafiei M, Shahcheraghi F, Saboora A, Ghazanfari T. The study of synergistic effects of n.butanolic Cyclamen coum extract and ciprofloxacin on inhibition of pseudomonas aeruginosa biofilm formation. Zistshinasii Mikruurganismha. 2015;3(12):25-32.

38. Pietta PG. Flavonoids as Antioxidants. Journal of Natural Products. 2000;63(7):1035-42.

39. Cushnie TT, Lamb AJ. Antimicrobial activity of flavonoids. International Journal of Antimicrobial Agents. 2005;26(5):343-56.

40. Prange ANS, Serek M, Bartsch M, Winkelmann T. Efficient and stable regeneration from protoplasts of Cyclamen coum Miller via somatic embryogenesis. Plant Cell Tissue Organ Cult. 2010;101(2):171-82.

\section{GRAPHICAL ABSTRACT}

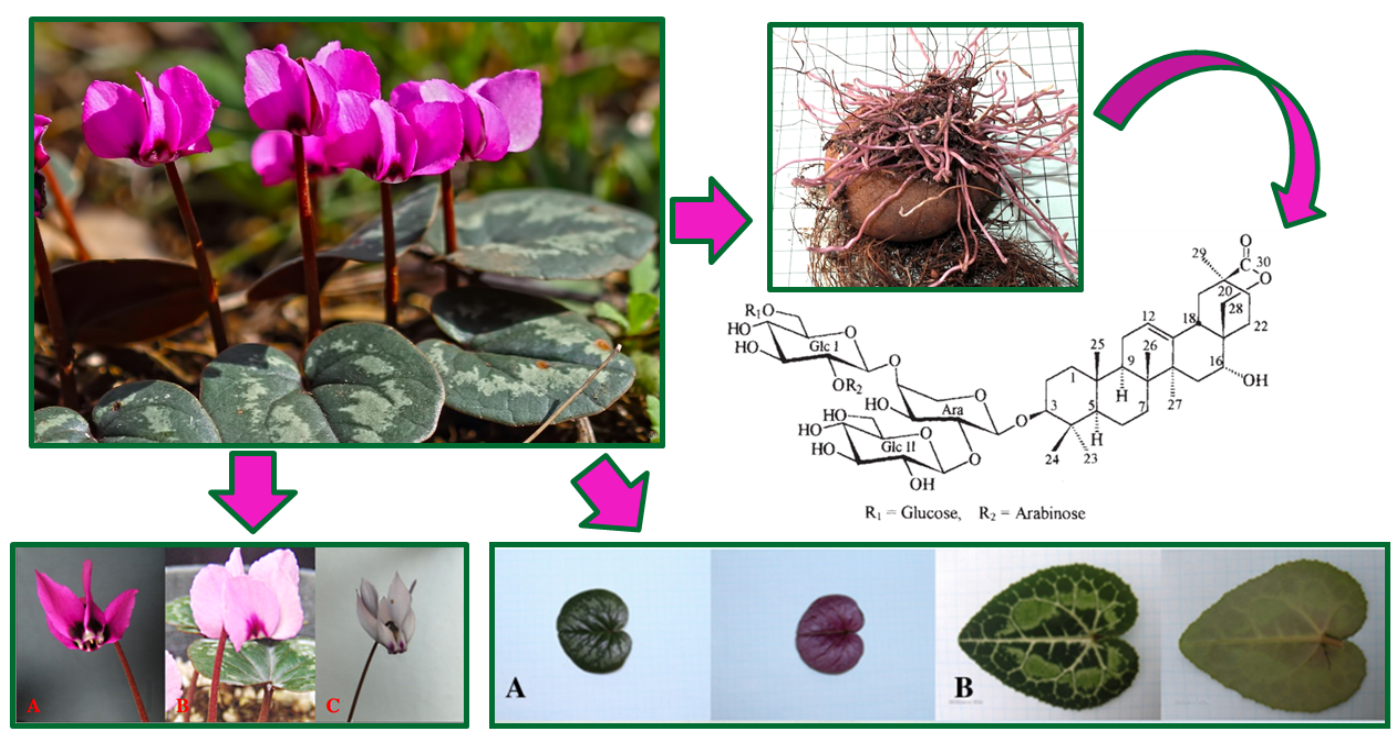

\section{ABOUT AUTHORS}

Bokov Dmitry Olegovich: Candidate of Pharmaceutical Sciences (Ph.D.), Associate Professor, Department of Pharmaceutical Natural Sciences, Department of Analytical, Physical and Colloid Chemistry, Institute of Pharmacy, Sechenov University; Laboratory of Food Chemistry, Federal Research Center for Nutrition, Biotechnology and Food Safety. Research Interests: pharmacognosy, analytical chemistry, investigation of the composition and content of biologically active compounds in crude herbal drugs using modern instrumental methods of analysis (HPLC with RID, UV, MS-MS detection, GC-MS).

Krasikova Maria Konstantinovna: Student, Institute of Pharmacy, Sechenov University. Research Interests: pharmacognosy, phytochemistry, Cyclamen genus plants, study of crude herbal drugs.

Sergunova Ekaterina Vyacheslavovna: Doctor of Pharmaceutical Sciences, Associate Professor, Professor of Department of Pharmaceutical Natural Sciences, Institute of Pharmacy, Sechenov University. Research Interests: pharmacognosy, influence of conservation methods on the composition and content of biologically active substances in medicinal plant materials.

Bobkova Natalya Vladimirovna: Doctor of Pharmaceutical Sciences, Associate Professor, professor of Natural Science Department, Institute of Pharmacy, Sechenov University. Research interests: pharmacognostic study of complex medicinal herbal remedies, microscopic investigation of medicinal plant materials.

Kovaleva Tatyana Yurievna: Candidate of Pharmaceutical Sciences (Ph.D.), Associate Professor, Department of Pharmaceutical Natural Sciences, Institute of Pharmacy, Sechenov University. Research interests: pharmacognosy, standardization of urological (diuretic), anxiolytic, nootropic medicinal herbal products.

Bondar Alina Aleksandrovna: Candidate of Pharmaceutical Sciences, Associate Professor of Pharmaceutical Natural Sciences Department, Institute of Pharmacy, Sechenov University. Research Interests: pharmaceutical botany, botanical and pharmacognostic study of Fabaceae, Rubiaceae, Asteraceae, Oleaceae medicinal plants of the Russian Federation flora.

Marakhova Anna Igorevna: Doctor of Pharmaceutical Sciences, Professor, head of Institute of Biochemical Technology and Nanotechnology, Peoples' friendship university of Russia (RUDN University). Research Interests: pharmacognosy, unification of physico-chemical methods of analysis of medicinal plant materials and herbal preparations, development and standardization of herbal medicines. 
Morokhina Svetlana Lvovna: Candidate of Pharmaceutical Sciences (Ph.D.) Preparatory faculty, Financial University under the Government of the Russian Federation (Financial University). Research Interests: pharmacognosy, standardization of crude herbal drugs and herbal preparations.

Krasnyuk Ivan Ivanovich (junior): Doctor of Pharmaceutical Sciences, Professor, Head of Department of Analytical, Physical and Colloid Chemistry, Institute of Pharmacy, Sechenov University. Research Interests: bioavailability increasing of dosage forms using solid dispersions.

Moiseev Dmitry Vladimirovich: Doctor of Pharmaceutical Sciences, Associate Professor, Head of the Chair of Standardization of Medicines, Vitebsk State Medical University. Research Interests: accelerated tests and stress-testing for raw materials, quality control of herbal substances and medicines, bioequivalence of medicines.

Cite this article: Bokov DO, Krasikova MK, Sergunova EV, Bobkova NV, Kovaleva TYu, Bondar AA, et al. Pharmacognostic, Phytochemical and Ethnopharmacological Potential of Cyclamen coum Mill. Pharmacog J. 2020;12(1):204-12. 